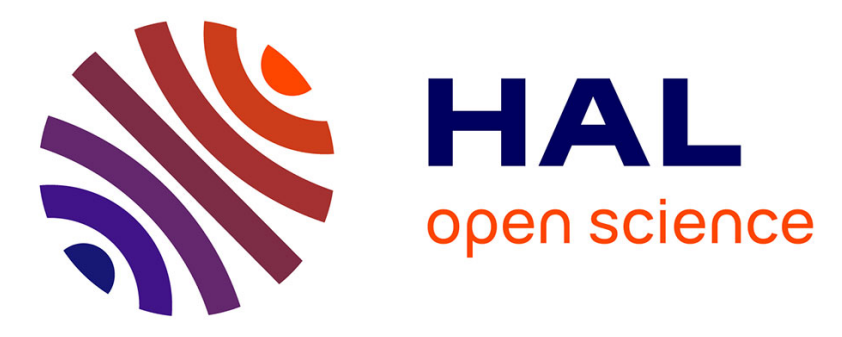

\title{
A genetic link between transform and hyper-extended margins
}

Laetitia Le Pourhiet, Dave A. May, Lucas Huille, Louise Watremez, Sylvie Leroy

\section{- To cite this version:}

Laetitia Le Pourhiet, Dave A. May, Lucas Huille, Louise Watremez, Sylvie Leroy. A genetic link between transform and hyper-extended margins. Earth and Planetary Science Letters, 2017, 465, pp.184-192. 10.1016/j.epsl.2017.02.043 . hal-01493997

\section{HAL Id: hal-01493997 https: / hal.sorbonne-universite.fr/hal-01493997}

Submitted on 22 Mar 2017

HAL is a multi-disciplinary open access archive for the deposit and dissemination of scientific research documents, whether they are published or not. The documents may come from teaching and research institutions in France or abroad, or from public or private research centers.
L'archive ouverte pluridisciplinaire HAL, est destinée au dépôt et à la diffusion de documents scientifiques de niveau recherche, publiés ou non, émanant des établissements d'enseignement et de recherche français ou étrangers, des laboratoires publics ou privés. 


\title{
A Genetic Link Between Transform and Hyper-Extended Margins
}

\author{
Laetitia Le Pourhiet, ${ }^{\mathrm{a}, *}$, Dave A. May ${ }^{\mathrm{b}}$, Lucas Huille ${ }^{\mathrm{a}}$, Louise Watremez ${ }^{\mathrm{a}}$, Sylvie Leroy ${ }^{\mathrm{a}}$ \\ ${ }^{a}$ Sorbonne Universités, UPMC Univ Paris 06, CNRS, Institut des Sciences de la Terre de Paris (iSTeP), 4 place \\ Jussieu 75005 Paris, France \\ ${ }^{b}$ Department of Earth Sciences, University of Oxford, Oxford, United Kingdom.
}

\begin{abstract}
The similarity between the geometry of the West African and South American coastlines is among one of the strongest natural observations supporting the plate tectonic paradigm. However, using classical plate tectonic approaches to model these conjugate transform margins results in a high degree of variability in palaeogeographic reconstructions. Using state-of-the-art 3D coupled thermo-mechanical numerical models, we simulate for the first time, crustal deformation at the onset of oceanisation along large offset oblique margins. Our models show that obliquity causes oceanic rift propagation to stall, resulting in an apparent polyphased tectonic evolution, and in some circumstances leads to the formation of hyper-extended margins. As a result, conjugate margins located at the edge of future fracture zones are highly asymmetric from rifting to spreading, with their lengths differing by a factor of 5 to 10, before the the final phase of break-up occurs. Accounting for this discrepancy should ameliorate future palaeogeographic reconstructions.

Keywords: continental rifting, passive margins, polyphasing, palaeogeography, geodynamic modelling
\end{abstract}

\section{Introduction}

The conceptual model of a transform margin (Fig. 1) is an adaptation from the kinematic model of a transform plate boundary of Francheteau and Le Pichon (1972). In this model, the interior of the plates are assumed to be rigid, except along diverging boundary segments (dark grey regions in Fig. 1). Even in deforming areas, the direction of transport is everywhere parallel to the relative plate motion. This model was subsequently adopted by marine geologists to understand the dynamics of extremely oblique passive margins (Mascle and Blarez, 1987).

Extending this idea, Basile et al. (1993) recognised that the edge of the divergent and transform

*laetitia.le_pourhiet@upmc.fr 
segments display different morphologies and vertical displacement history. They introduced the terms of concave and convex transform divergent segments based on the shape of the of oceanic domain (Fig. 1A). Within the rigid transform margin models, these differences are explained by the interaction of the margin with the ridge during the early stage of drifting (Fig. 1B) which causes a secondary heat pulse and uplift (Rüpke et al., 2010). This process also affects the transform margin between the stages depicted in Fig. 1B and Fig. 1C, and according to the rigid kinematic model, without resulting in any horizontal deformation.

Using the transform margin model to reconstruct plates motion is known to fail at large offsets. Attempts to geometrically match conjugate margins typically lead to isolated pockets of oceanic crust along rifted segments (Bullard et al., 1965; Rabinowitz and LaBrecque, 1979; Unternehr et al., 1988), or overlapping regions of continental blocks (Moulin et al., 2009). The failure of the classical model is most frequently explained by pre break-up deformation (Torsvik et al., 2009), or, as suggested by Vink (1982); Turner et al. (2003), by a delay in the break-up along the oblique segment. Both explanations clearly indicate that tectonic plates deviate from the rigid kinematic block theory outlined in Fig. 1.

Paleogeographic reconstructions can account for distributed strain, but they require quantitative constraints on the rate of deformation, and the obliquity of the structures which accommodate the strain. Recently, high-resolution two-dimensional dynamic models of break-up have been utilised to better understand the syn-rift deformation and provide constraints for paleogeographic reconstructions (Brune et al., 2014, 2016). Nevertheless, the conclusions drawn from such models need to be demonstrated in oblique rifting context. Modelling oblique setting naturally mandates the usage of three-dimensional dynamic models.

To date, two classes of 3D rift models have been considered. The first class have been designed to focus on the localisation of the deformation within large oblique weak zone (Tron and Brun, 1991; Mart and Dauteuil, 1999; McClay, 1990; van Wijk, 2005; Brune, 2014; Heine and Brune, 2014), whilst the second class focus on the strain localisation within the transfer zone between two en-echellon grabens by using two offset weak zones (Vendeville and Le Calvez, 1995; Gerya, 2010; Allken et al., 2011, 2012, 2013; Liao and Gerya, 2015).

Performing dynamic numerical models of large offset (100's km), magma poor, oblique passive margins such as Rio Muni in West Africa(Turner et al., 2003), Alula Fartak in the Gulf of Aden (Leroy et al., 2012), or the Ghana transform margin (Basile et al., 1993), requires three-dimensional 


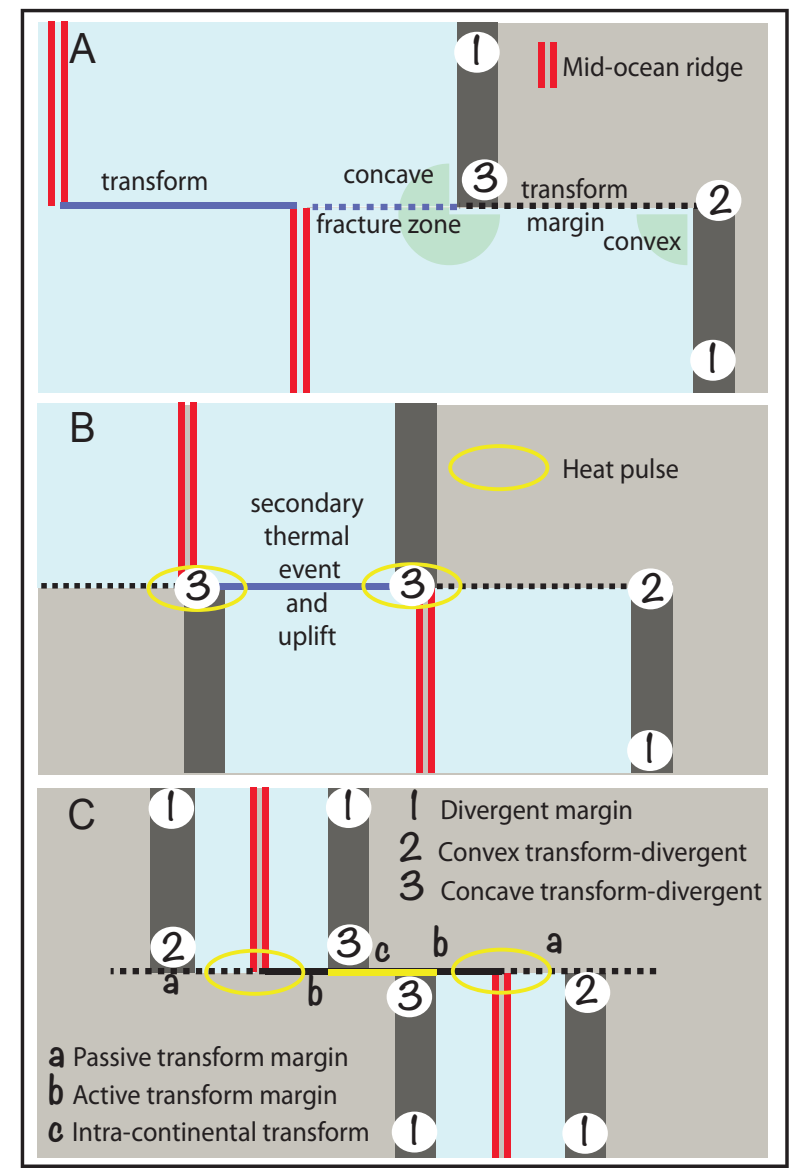

Figure 1: Illustration of the kinematic model of transform margin formation. Modified from Francheteau and Le Pichon (1972) and Basile et al. (1993). Light grey represents normal thickness continental crust, dark grey regions represent the thinned continental crust and light blue regions indicate oceanic crust. A) Post rift stage illustrating the location of concave and convex transform divergent margins; B) Latest stage of transform margin activity showing that the mid-ocean ridge interacts thermally with the concave transform margin, long after break-up; C) Formation of the transform margin.

experiments which include: full thermo-mechanical coupling, large deformation spanning at least 30 Myr of evolution and sufficiently high spatial resolution to capture accurately the deformation across a $300 \mathrm{~km} \times 200 \mathrm{~km}$ transfer zone.

Due to technical limitations, none of the previous 3D numerical studies could simultaneously satisfy all of these requirements. Time scales of evolution rarely exceeded 5 Myr (Choi et al., 2008; Gerya, 2010, 2013; Allken et al., 2011, 2012, 2013), and the offset across the diverging segments reached, at maximum $50 \mathrm{~km}$, within a model domain (in map view) of $100 \mathrm{~km} \times 100 \mathrm{~km}$ (Choi et al., 2008; Gerya, 2010, 2013; Allken et al., 2012; Liao and Gerya, 2015). Heine and Brune (2014) modelled oblique rifting at the scale of the equatorial Atlantic, however their models did not have sufficient spatial resolution to resolve fault patterns in the crust. In this work, we utilise 
a newly developed, state-of-the-art massively parallel computational framework for studying 3D lithospheric deformation to surmount all of the aforementioned technical challenges required to simulate models of oblique passive margins.

\section{Method}

\subsection{Model set-up}

The original kinematic model (Mascle and Blarez, 1987) supports that transform margins are expected form at bridging rift segments, therefore we adopted the model design which includes two offset weak zones. We consider a lithosphere scale model domain (Fig. 2A) representing $600 \times 150 \times 1200 \mathrm{~km}^{3}$. Apart from the dimensions of the physical domain, the model configuration is similar to other models designed to simulate strain localisation of oblique transfer zones (Vendeville and Le Calvez, 1995; Gerya, 2010; Allken et al., 2011, 2013, 2012; Liao and Gerya, 2015) and incorporates a minimum amount of complexity.

All models consist of an initially horizontally layered hypothetical lithosphere which includes mantle, lower crust and upper crust (Fig. 2A). The Moho is originally located at $40 \mathrm{~km}$ depth and the boundary between lower and upper crust is located at $20 \mathrm{~km}$ depth. To simulate extensional systems, we impose a normal velocity with magnitude $1 \mathrm{~cm} / \mathrm{yr}$, along each face whose normal points in the $x$ direction. This magnitude of velocity is quite standard for modelling continental extension and was previously used by Watremez et al. (2013) to model the opening of the Gulf of Aden, a young example of oblique continental extension. Material leaving the domain across these faces is compensated by a constant infilling normal velocity $(2.5 \mathrm{~mm} / \mathrm{yr})$ at the base of the models. Both the inflow and outflow boundaries prescribed that the shear stress is zero. Zero normal velocity and shear stress (free slip) are prescribed on the domain faces with normal pointing in the $z$-direction. The top boundary of the domain is defined to be a free surface (i.e. zero stress).

The initial crustal density structure is the same in all the models and corresponds to a density of $2700 \mathrm{~kg} / \mathrm{m}^{3}$ in the upper crust and $2800 \mathrm{~kg} / \mathrm{m}^{3}$ in the lower crust. The initial geotherm we used corresponds to a half-space cooling model after $300 \mathrm{Myr}$ (see Fig. 2C). All three regions employ an approximate Arrhenius type flow law (see Appendix A, Eq. (A.7)). The reference viscosity of the lower crust was varied in order to test whether lithosphere previously involved in orogenic processes reacts differently from a regular (REG) lithosphere. The Post Orogenic (PO) lithosphere assumes that the lower crust constitutes sedimentary material that has previously been 


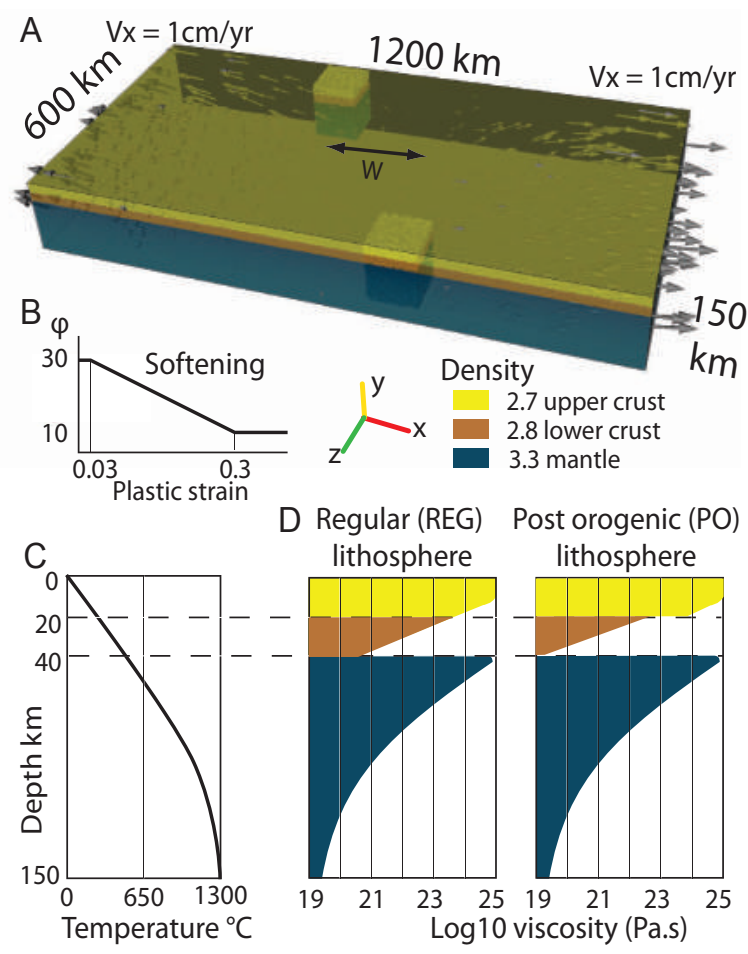

Figure 2: Model definition. A) 3D domain with extensional boundary conditions and the outline of pre-existing weak zones offset by a distance $W$; B) Rheological softening law in the crust; C) Initial geotherm; D) Viscosity profile for the coupled (REG) and decoupled (PO) lithosphere obtained using the initial geotherm.

buried underneath a regular crust (Huet et al., 2011) and therefore possesses a viscosity lower than that in the regular lower crust. This produces an inverted rheological stratification of the crust (Fig. 2D). The viscosity profiles obtained for the REG and PO lithosphere models are shown in Fig. 2D

In order to avoid unrealistically high stresses and topography, material strength is limited by frictional brittle failure with an additional plastic yield strength set to $300 \mathrm{MPa}$ (Watremez et al., 2013). Localisation is enhanced by frictional softening with strain (Fig. 2B). Softening is enhanced in the mantle (see Table 1) to approximate the effect of serpentinisation on the brittle behaviour. Initially, each material point in the domain is assigned a random plastic strain value between 0 and 0.03. In the domain, we impose two weak zones, offset by a distance $W$, each defining a $100 \times 120 \times 100 \mathrm{~km}^{3}$ volume (depicted in Fig. 2 A). Within each weak zone, the amplitude of the initial random plastic strain is ten times larger (i.e. varies between 0 and 0.3 ) compared with the initial damage defined throughout the rest of the domain. All parameters are listed in the Table 1.

We will first present the results of 8 simulations, examining how: (i) the initial offset $W$ 


\begin{tabular}{ccc|rrr}
\hline quantity & name & unit & REG crust & PO crust & mantle \\
\hline$\eta_{0}$ & reference viscosity & Pa s & $10^{27}$ & $10^{26}$ & $10^{30}$ \\
$\theta$ & char. temperature & ${ }^{\circ} \mathrm{C}^{-1}$ & $2 \times 10^{-2}$ & $2 \times 10^{-2}$ & $1.8 \times 10^{-2}$ \\
$\phi_{0}$ & friction angle & $\circ$ & 30 & 30 & 30 \\
$C_{0}$ & cohesion & $\mathrm{Pa}$ & $2 \times 10^{7}$ & $2 \times 10^{7}$ & $2 \times 10^{7}$ \\
$\tau_{\text {mms }}$ & maximum strength & $\mathrm{Pa}$ & $2 \times 10^{8}$ & $2 \times 10^{8}$ & $3 \times 10^{8}$ \\
\hline$\phi_{\infty}$ & min. friction angle & $\circ$ & 6 & 6 & 6 \\
$\varepsilon_{\infty}^{p}$ & softening char. strain & - & 0.3 & 0.3 & 0.15171 \\
\hline$\rho_{0}$ & density & $\mathrm{kg} \mathrm{m}^{-3}$ & $2.7 / 2.8 \times 10^{3}$ & $2.7 / 2.8 \times 10^{3}$ & $3.3 \times 10^{3}$ \\
$\alpha$ & thermal expansion & ${ }^{\circ} \mathrm{C}^{-1}$ & $2 \times 10^{-5}$ & $2 \times 10^{-5}$ & $2 \times 10^{-5}$ \\
$\beta$ & compressibility & $\mathrm{Pa}^{-1}$ & 0 & 0 & $3 \times 10^{-12}$ \\
\hline$\kappa$ & thermal diffusivity & $\mathrm{m}^{2} \mathrm{~s}^{-1}$ & $10^{-6}$ & $10^{-6}$ & $10^{-6}$ \\
\hline
\end{tabular}

Table 1: Physical properties of the different materials. Regular (REG) crust is more viscous than Post Orogenic crust (PO). The relationship between parameters listed and the equations solved by the thermo-mechanical numerical model are elaborated upon in Appendix A.

between the weak zones (see Fig. 2A); and (ii) the initial mechanical coupling between the crust and lithospheric mantle (REG versus PO in Fig. 2B) influences the linkage between rift segments. Following that, we concentrate on the dynamics of divergent segments which link at moderate to large offset values.

\subsection{Modelling}

This study uses pTatin3D (May et al., 2014, 2015) - a highly scalable, massively parallel implementation of the finite element method which employs an Arbitrary Lagrangian Eulerian discretisation, together with the material point method. The equations governing viscous flow (see Appendix A) together with a free surface boundary condition are accurately resolved through the use of high order stable elements $\left(Q_{2}-P_{1}\right)$. Material properties and history variables are assigned to material points contained within the computational domain. Material points are allowed to exit (or enter) the model domain according to boundary conditions. Details related to the non-linear solver are provided in Appendix B. 
Owing to this new generation code, it has become possible to discretise a $600 \times 150 \times 1200 \mathrm{~km}^{3}$ lithosphere domain using $128 \times 32 \times 256$ elements, leading to spatial resolution of $5 \mathrm{~km}$. This discrete system of algebraic equations defines a highly non-linear problem (due to the rheology used) with over $29 \times 10^{6}$ degrees of freedom. Each simulation integrates deformation over a time span of 25 to 35 Myr, which corresponds to $~ 2000$ time steps on average.

\subsection{Post-processing}

In this study, we are interested in the obliquity of tectonic structure with the stretching direction. Hence, we have chosen to represent the simulation results primarily in map view. The results are presented in terms of surface elevation, Moho elevation and active fault trends map. As the models have a free surface, the topography is simply the elevation of the nodes located at the surface of the model relative to the upper right corner of each map.

The different lithologies are stored on markers in the code and used to compute effective viscosity and density (see Appendix A). In order to reduce the amount of data per stored time step to approximately 500 MBytes (250 GBytes per simulations), we only store the density, viscosity and plastic strain averaged over each element.

In order to extract the Moho, we examine all cells with an average density larger than 3200 $\mathrm{kg} / \mathrm{m}^{3}$ and extract the cells average $y$ coordinate. For a given column in the $x-z$ plane, the Moho is defined via the maximum of these $y$ coordinates (refer to Fig. 2A for coordinate system used). As the models include neither melt nor, true oceanic crust, we define the ocean-continent boundary by attributing a continental affinity to all surface cells in which densities are lower than $3200 \mathrm{~kg} / \mathrm{m}^{3}$.

Faults in these numerical models are shear bands with a finite thickness, typically on the order of one to two elements. Here we split the components of shear that corresponds to vertical direction, i.e. the dip slip component $\left(\dot{\varepsilon}_{x y}\right.$ and $\left.\dot{\varepsilon}_{y z}\right)$ from the component of shear in the horizontal direction, i.e. the transform component $\left(\dot{\varepsilon}_{x z}\right)$ and we only visualise the zones where these components are larger than the background strain rate $\left(5 \times 10^{-16} \mathrm{~s}^{-1}\right)$ as these regions correspond to locations where strain rate has localised. 


\section{Results and discussion}

\subsection{Rift linkage}

To first order, models with a weak lower crust (PO) display distributed normal faulting with faults trending orthogonal to the direction of stretching while this distributed small wavelength deformation is absent in the strong lower crust models (REG). This contrasting behaviour is predicted by previous 2D numerical models (Huismans and Beaumont, 2007). More surprising is that the propagation of divergent rift segments occurs faster in the decoupled lithosphere (Fig. 3, see PO models at $10 \mathrm{Myr}$ ), compared to the coupled lithosphere model (Fig. 3, see REG models at 10 Myr).

The final outcome of the models considered fall into one of four cases outlined by the different colours of the small insets panels in Fig. 3. At small $(100 \mathrm{~km})$ and extremely large initial offset $(400 \mathrm{~km})$, the rheology of the lower crust does not greatly influence the results within the first 25 Myr of evolution. With an offset of $100 \mathrm{~km}$, oblique margins form rapidly, followed by oblique spreading. For offsets of $400 \mathrm{~km}$, propagating rifts do not interact mechanically.

Obliquity is quantified as the angle between the strike and the stretching direction, a low angle therefore corresponds to a high obliquity. For moderate to large initial offsets, the rheology controls the transition from an oblique margin $\left(45^{\circ}\right)$, to an extremely oblique margin $\left(<30^{\circ}\right)$, and a failed oblique rift (Fig. 3). For an offset of $200 \mathrm{~km}$, the obliquity of the transfer zone is higher when using a PO lithosphere, compared to when using a REG lithosphere. The maximum offset between two linking weak zones increases with the strength of the lithosphere (compare the models with $300 \mathrm{~km}$ offset in Fig. 3).

Examining the snapshots of the models at 25 Myr (Fig. 3), it is clear that, the larger the offset, the longer it takes to localise the deformation on the oblique segment. As a result, the delay between the break-up on the propagating divergent rift segment, measured as the first break-up time in the pre-existing weak zones and the final oblique break-up, increases from 6 Myr for 100 $\mathrm{km}$ offset to $25 \mathrm{Myr}$ for a $300 \mathrm{~km}$ initial offset (see supplementary movies of the experiments). During this period, mid-ocean ridge propagation is stalled, but distributed continental extension accommodates the divergence at the tip of the ridge.

The models in which early faults (those active at 10 Myr in Fig. 3) strike perpendicular to the stretching direction result in a larger final obliquity than models which develop early structures that are oblique to the stretching direction. In all the models, the orientation and existence of 
early structures (those active at 10 Myr in Fig. 3) is controlled by the rheology of the lower crust, and, to a lesser extent, by the initial offset. This led us to speculate that, in nature, pre-existing structures reactivated during the early stages of rifting (Bellahsen et al., 2006) could possibly

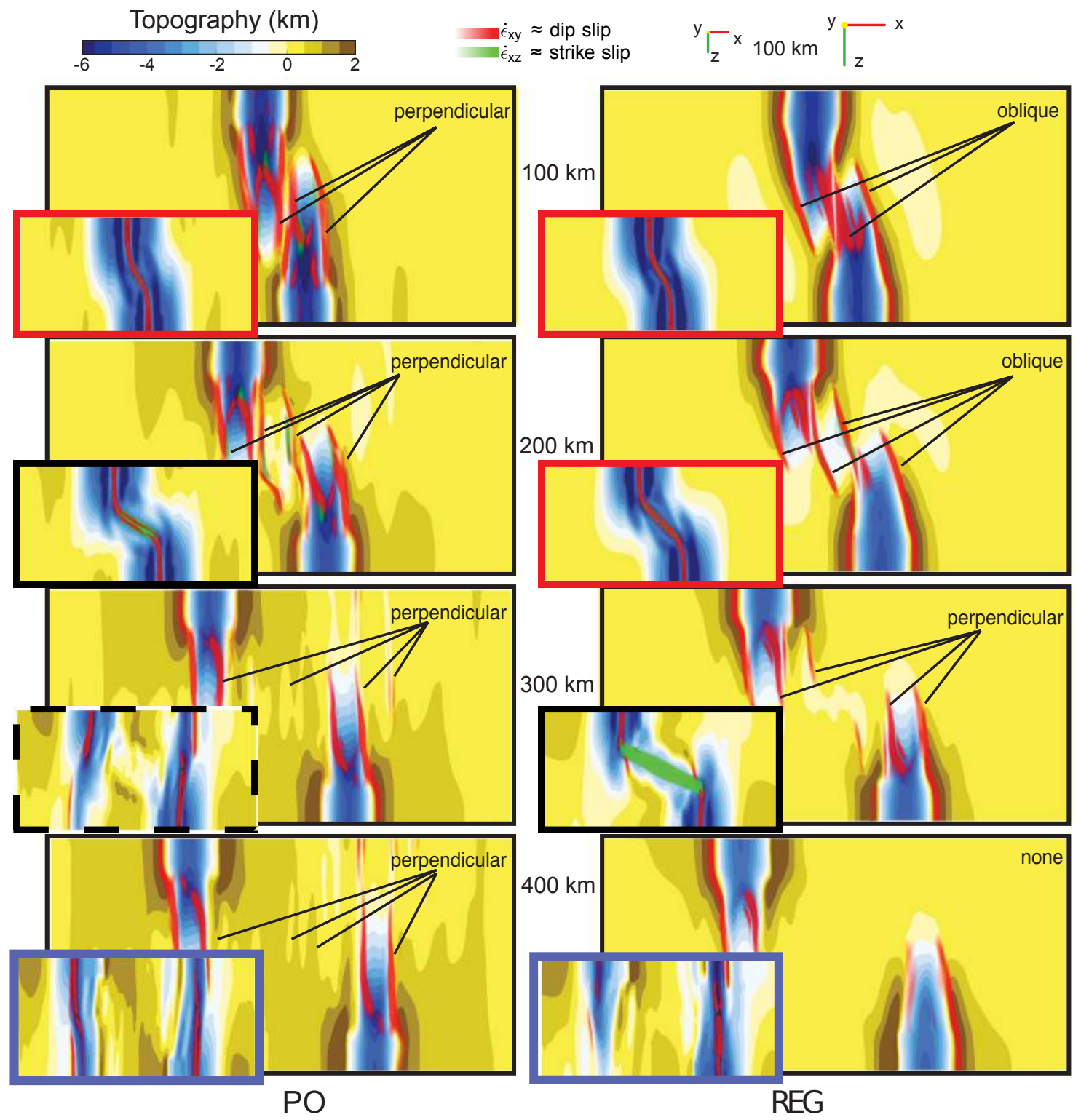

Figure 3: Results of the parametric study. Map view of the topography of all the models after $10 \mathrm{Myr}$ (large insets) and $25 \mathrm{Myr}$ (small insets) with major active faults outlined as shade of red (dip slip kinematics) and green (strike slip kinematic). At $10 \mathrm{Myr}$, distributed small wave length faults striking perpendicular to the direction of stretching forms in the post orogenic models (Left) while large oblique normal faults forms in the regular crust models (Right). At $25 \mathrm{Myr}$, coloured boxes indicate models with oblique margins ( $45^{\circ}$, red), with extremely oblique margins $\left(<30^{\circ}\right.$, black), abandoned transfer zone (dashed) and in which segments did not link at all (blue). Supplementary movies are provided for experiments REG-100 km, REG-300 km and PO-100 km, PO-300 km using the same colour scales as this figure. 
influence the final obliquity of the margin.

\subsection{Initial weak zones spacing and linkage}

Previous studies with no thermal coupling have reported that linkage does not occur when notch spacing exceeds the thickness of the brittle layer (Vendeville and Le Calvez, 1995; Allken et al., 2012). At lithospheric scale, this limit would correspond to $W \leq 100 \mathrm{~km}$. In our models which account for thermal coupling, the linkage between divergent segments is obtained for much larger offsets, upto 3-4 times the thickness of the brittle layer.

In analogue models, the interactions between grabens has been found to be less efficient when the weak zones overlap, but no significant differences were observed between models with nonoverlapping weak zones and models with underlapping weak zones (Le Calvez and Vendeville, 2002). Using dynamic numerical models to study these geometrical effects in more details, Allken et al. (2013) showed that a larger amount of underlap favours linkage because more diffuse strain can occur in the transfer zone before the imposed rift segment propagates. In a previous study, Allken et al. (2012) showed that linkage occurs with a larger offset if a weak and thick ductile layer is present at the base of the crust. With our lithospheric scale models, we find that it is easier to link lithospheric scale rift segment when the lower crust is resistant. This is somewhat contradictory to Allken et al. (2012) conclusions. Yet, we note that their models neglected the strain localisation in the lithospheric mantle and were devoid of any thermo-mechanical coupling. The two studies can be reconciled by recognising that at the scale of our models, the weak lower crust of Allken et al. (2012) corresponds to our weak asthenosphere. The final strain rate and linkage pattern of our models actually always occurred within the low viscosity lower crust class defined in Allken et al. (2012), independently of the viscosity of the lower crust. We now focus on the dynamics of models in which linkage occur at large off-set in our parametric study.

\subsection{Dynamics of large offset break-up}

Before oblique localisation occurs (Fig. 4A), the two divergent segments are always separated by en-echellon deep intra-continental basins as clearly indicated by the topography. Depending on the dynamics of break-up, oblique or extremely oblique, their thermal and tectonic histories are different. The vertical loads associated with the presence of hot asthenospheric mantle and lateral variation in crustal thickness result in the flexural bending of plates. Where crustal thinning 

break-up.

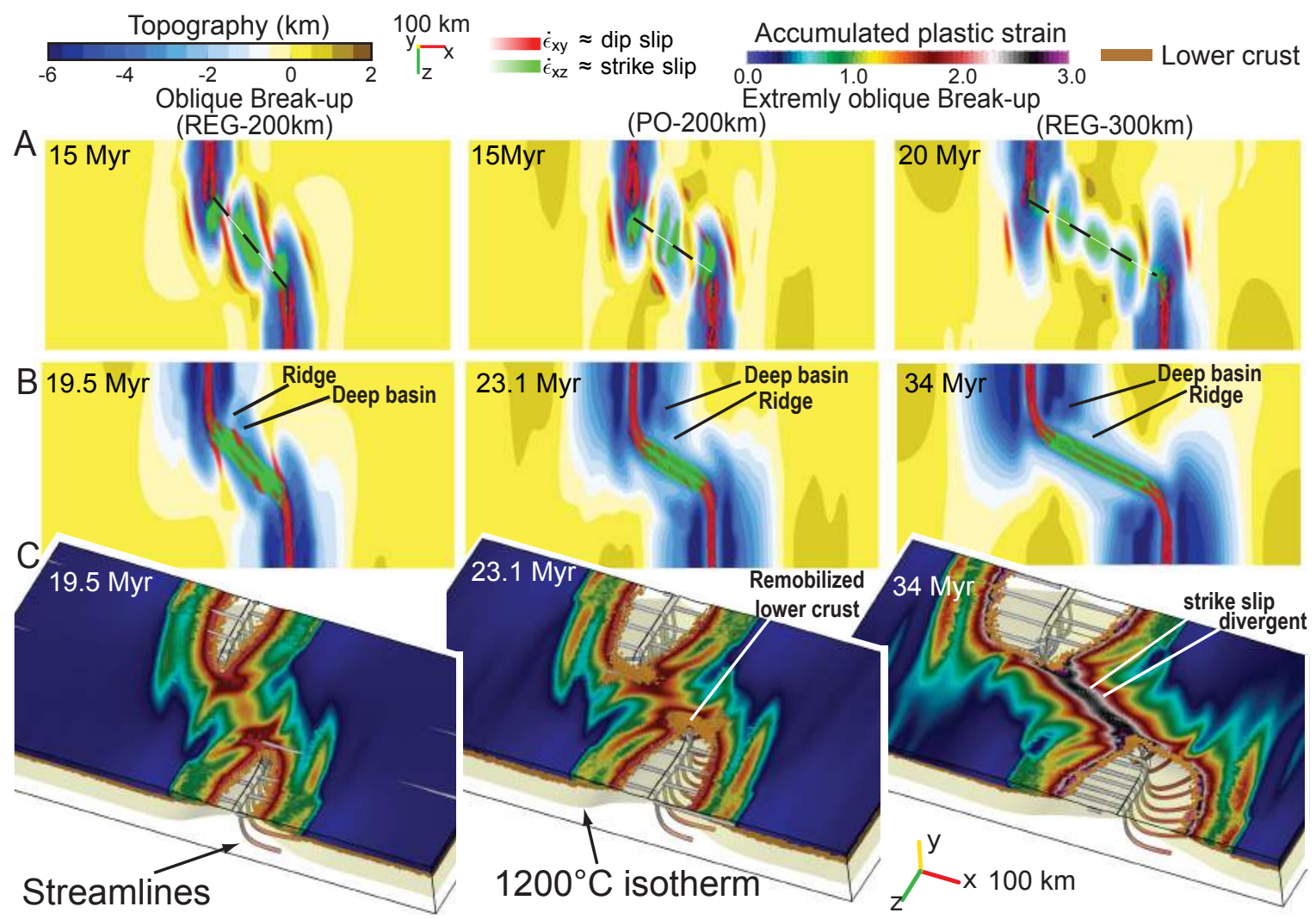

Figure 4: Map view of the topography with major active faults outlined via a shade of red (dip-slip kinematics) and green (strike slip kinematic). Timing corresponds to A) onset of strike slip strain localisation in the transfer zone and B) incipient break-up. C) Accumulated plastic strain (main faults) in the upper crust. The oceanic lithosphere has been removed to outline the ocean-continent boundary and to highlight the asymmetry in asthenospheric flow line feeding the mid-oceanic ridges. Exhumed lower crustal material is shown in brown.

For the model which results in oblique break-up (REG-200 km) in Fig. 4, the latest stage of oblique localisation occurs within the center of the early oblique basin. Looking at the accumulated plastic strain as a proxy for major fault orientation, one observes that the oblique break-up does not cut across any pre-existing structures with a different orientation. The rotation of the active structure with time (Fig. 4A,B and supplementary movie REG-200km) shows that the early structures rotated continuously between the two diverging segments to reach their final orientations. As a result, the remnants of the early deep basins forms an oblique margin which is separated from the divergent segment by topographic ridges which are orthogonal to the direction of extension.

In models which result in extremely oblique break-up (PO-200 km and REG-300 km) in Fig. 4, strike slip localisation occurs along a strike slip structure, which cross-cut the initial en-echelon 
basins (Fig. 4B). The supplementary movies (PO-200km and REG-300km) clearly indicate, this structure did not form by continuous rotation of the earlier structures. At the onset of localization in the mantle, no oblique structures are visible at the surface (Fig. 4A), yet small portion of the early basins deforms with strike slip kinematics. These local spots of green shades outline the direction of the still deep seated mantle necking structure which will reach the surface at the stage depicted on Fig. 4B.

The accumulated plastic strain (Fig. 4C) show that extremely oblique break-up segments cut across the early rift structures. For the REG-300 km model, the shade of white in the plastic strain highlights the orientation of the structures during break-up and indicates that break up occurs on pure transform segments separated by divergent segments. As crustal thinning, inherited from the earlier phase, is not parallel to lithospheric thinning, a topographic ridge forms parallel to the oblique margins.

The delay between the divergent margin break-up and the onset of oblique break-up causes the formation of a large oceanic domain prior to complete break-up. They are displayed as transparent on Fig. 4C. Their size increases with increasing initial offset and decreasing lower crustal strength.

All the models show that these oceanic domains are unevenly distributed across the midoceanic ridge and that the asthenospheric flow feeding these ridges is also asymmetric (Fig. $4 \mathrm{C}$ ). This suggests that early spreading is not purely divergent in the model. The magnetic anomalies from the Gulf of Aden (Fig. 5A) and West Africa (Fig. 5B) show the presence of oblique stripes, and ductile shear indicators such as S-C structures, in good agreement with the prediction of our models.

For strong lower crustal rheology (REG-models, Fig. 4C the asymmetric spreading occur in the oceanic domain. For weak lower crustal rheology (PO-model, Fig. 4C), the lower crust is remobilized and spreads to accommodate the asymmetry. This suggest that the rheology of the lower crust controls whether re-mobilized crustal material (Ranero and Pérez-Gussinyé, 2010; Unternehr et al., 2010), or exhumed mantle material (Pérez-Gussinyé et al., 2001), accommodates the latest stage of deformation.

The Moho is very shallow at the tip of the oceanic domain (Fig. 6A), highlighting a large amount of continental extension. The 3D models show that large initial offset causes an asymmetry in extension and the formation of hyper-extended margins. However, these hyper-extended basins only mark the tip of en-echellon diverging rift segments which have stalled during the long-lasting 


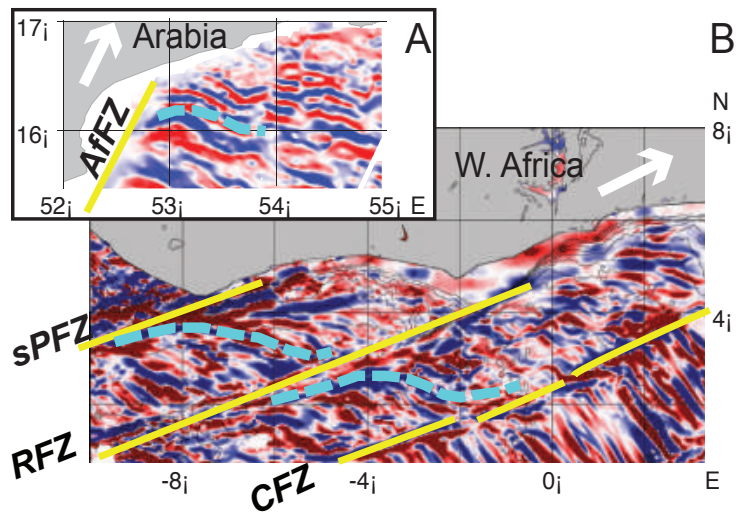

Figure 5: textbfMap view of the gradient of magnetic field. A) In the Gulf of Aden at the Corner of Alula Fartak fracture zone (AfFZ) (Leroy et al., 2010). B) Along the West African margin (Maus et al., 2009) nearby the Saint Paul Fracture Zone (sPFZ), the Romanche Fracture Zone (RFZ) and the Chain Fracture Zone (CFZ). In both cases that the magnetic anomalies (dashed cyan line) are not perpendicular to the direction of spreading (white arrow), nor to the fracture zone (yellow line) close to the transform margin.

strain localisation along the oblique segments. They do not indicate the direction of propagation of oceanisation as suggested in the Gulf of Aden (Manighetti et al., 1997).

\subsection{A new model for transform margins}

Fig. 6A highlights the coastlines (cyan lines) from the conjugate convex (3) and concave (2) transform divergent margins produced by model REG-300 km at the end of continental break-up. The coastlines are of very different length. The concave margin is only a few tens of kilometers long, whilst its convex conjugate can be as long as $200 \mathrm{~km}$. Fig. 6B represents a hypothetical passive margin that would result from model REG-300 km. Combining the $\sim 250 \mathrm{~km}$ of the oblique segment (yellow line) and the $200 \mathrm{~km}$ segment of the convex margin, the coastline which trends extremely oblique to the direction of stretching, reaches a length of $\sim 450 \mathrm{~km}$. This is comparable in length to the transform margins in the equatorial Atlantic (Fig. 5B).

Due to the anti-symmetric extension occurring on the opposite segment, a coastline of similar length exists on the right block. However, trying to reassemble the left and right blocks using the rigid transform margin model (Fig. 6C) shifts the location of the early deep basins, while our models indicate these features were aligned during the 15 to $25 \mathrm{Myr}$ of extension that preceded oblique break-up (Figs. 4 and $6 \mathrm{~A}$ ).

In order to perform the reconstruction correctly, the initial conditions, the pre-rift and the early normal faults located on the transform segment must be used to restore the onset of break-up stage which is displayed in Fig. 6A. 
This should leave behind large remnants of divergent oceanic domain, exhumed lower crustal domain and hyper-extended margins, which can be overlapped based on the magnetic anomaly of the purely divergent segments. From the results of our numerical models, a good proxy for the timing of the final break-up is the formation of the marginal ridge which cross-cut the early basins. The flexural uplift should be marked by an unconformity between the syn-rift and post-rift sediments in the deep basins located at its back.

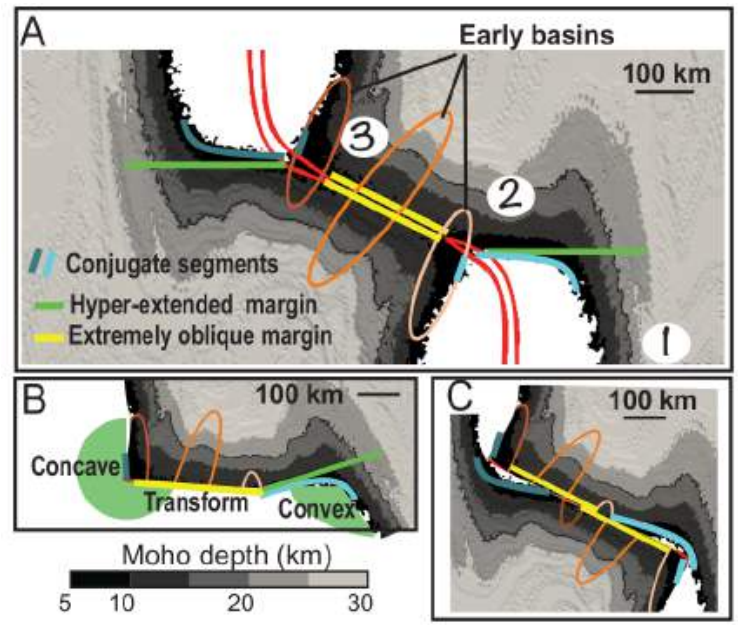

Figure 6: A) Map view of the Moho depth for the REG model with a $300 \mathrm{~km}$ offset with the main structures; 1 , 2 and 3 indicate respectively the divergent, convex and concave transform divergent margins; B) Representation of the anticipated passive margin, long time after continental rifting with annotations corresponding to the original model represented on Fig. 1A; C) Schematic reconstruction using the rigid plate kinematic model and showing the misfit of the early rift structures if one does not first reconstruct the break-up stage displayed in A)

The deep basins formed in the early stage of rifting present a good potential for hydrocarbons because they were tectonically isolated from the well oxygenated water that fills the basins forming along the pre-imposed divergent segments. However, this potential also depends on the dynamics of the break-up, i.e. oblique or extremely oblique. In the first case, they rotate to align with the oblique mid-oceanic ridge. In the second case, some of these basins are preserved in the intrado of the topographic ridge, proctecting them from heat and promoting very early migration. As a result, the concave transform divergent margin (zone 3 in Fig. 1 and $6 \mathrm{~A}$ ) is constituted by deep, potentially hydrocarbon rich, basins formed in the early stages of rifting which are absent from the convex divergent margins. 


\section{Conclusions}

Using modern, state-of-the-art, high performance computing tools has allowed us to simulate dynamic, 3D lithospheric scale oblique rifting scenarios with the necessary spatial resolution. Our results show that simple set-up with cylindrical and constant boundary conditions produce a level of complexity in term of asymmetry and poly-phasing of deformation that could only be obtained with more complex model configurations or boundary conditions in 2D (Brune et al., 2014; Huismans and Beaumont, 2011, 2007).

Our models predict that the break-up of extremely oblique segments occurs 10 to 25 Myr after the break-up of the divergent segments. During this period, stalling normal rift propagation leads to the formation of deep anoxic basins, along with micro continental ribbons which form patterns similar to those observed in northern Atlantic profiles (Péron-Pinvidic and Manatschal, 2010) and in Angola-like hyper-extended margins (Unternehr et al., 2010).

Natural fracture zones and transform margins are not defined by line segments, but rather a $100 \mathrm{~km}$ diffuse zone of deformation (Fig. 5) where significant asymmetry can be accommodated by exhumation of lower crustal material, and/or asymmetry of the spreading. These deformation zones record the temporal history of several phases of deformation occurring prior to oblique break-up. Consequently, attempting to reconstruct plate motions with rigid plate transform margin model is impossible. Our new high resolution 3D dynamic models can help predict where, and when, significant amounts of stretching and wrenching are expected to occur. Such results will help to further improve the reliability and accuracy of future paleogeographic reconstructions.

\section{Acknowledgements}

Maps were realised with GMT, post processing with Paraview. The paper benefited of discussions with C. Basile, D. Aslanian and P. De Clarens through the Action Marge Program. D. A. May and L. Le Pourhiet acknowledge the Swiss National Supercomputing Centre (CSCS) for compute time on Piz Dora, obtained under the production proposal grant 20131011-2135237.

\section{Appendix A. Governing Equations}

The mechanical component of pTatin3D solves the conservation of momentum for incompressible, highly non-linear viscous fluids. The conservation of momentum for such a fluid is given 
by

$$
\left[2 \eta \dot{\varepsilon}_{i j}(\boldsymbol{u})\right]_{, j}-p_{, i}=f_{i},
$$

where $\boldsymbol{u}, p$ are the fluid velocity and pressure, $\eta$ is the shear viscosity, $f_{i}$ is the body force and the strain rate operator $\dot{\varepsilon}_{i j}$ is given by

$$
\dot{\varepsilon}_{i j}(\boldsymbol{u}):=\frac{1}{2}\left(u_{i, j}+u_{j, i}\right)
$$

The total stress $\sigma_{i j}$ is given by

$$
\sigma_{i j}=\tau_{i j}-\delta_{i j} p, \quad \text { where } \tau_{i j}=2 \eta \dot{\varepsilon}_{i j}
$$

Simplified mass conservation is achieved through assuming incompressibility

$$
u_{k, k}=0
$$

The forcing term in the momentum equation reflects changes in buoyancy associated with thermal contraction/expansion (Boussinesq approximation), or compositional variations between different rock types following

$$
\boldsymbol{f}=\rho_{0}\left(1-\alpha\left(T-T_{0}\right)+\beta\left(p-p_{0}\right)\right) \hat{\boldsymbol{g}}
$$

where $\rho_{0}$ is the compositional density of the rock as measured at the reference temperature $T_{0}$ and pressure $p_{0}, \hat{\boldsymbol{g}}$ is the gravity vector, $\alpha, \beta$ are the coefficients of thermal expansion and adiabatic compressibility respectively and $T$ is the temperature. The evolution of temperature is given by the following conservation equation

$$
\frac{\partial T}{\partial t}+\boldsymbol{u} \cdot \nabla T=\frac{\partial}{\partial x_{i}}\left(\kappa \frac{\partial T}{\partial x_{i}}\right)
$$

where $\kappa=k /\left(\rho C_{p}\right)$ is the thermal diffusivity.

Thermally activated creep mechanisms defining the viscous strength of rock, $\eta^{\prime}$ are approximated by the Frank-Kamenetskii flow rule

$$
\eta^{\prime}=\eta_{0} \exp (-\theta T)
$$

where the parameters $\eta_{0}, \theta$ account for the local chemical composition of the rock. These coefficients are also carried by the markers. Pressure and strain rate dependence are introduced by limiting the effective viscosity so that stresses in the model do not exceed the Drucker-Prager yield stress

$$
\tau_{y}=\min \left[p \sin \phi\left(\epsilon^{p}\right)+C_{0} \cos \phi\left(\epsilon^{p}\right), \tau_{\mathrm{mms}}\right]
$$


which is limited a maximum Mises stress, $\tau_{\mathrm{mms}}$. The cohesion $C_{0}$ is regarded to be constant, however the internal friction angle $\phi$ is assumed to decrease as a function of the accumulated plastic strain $\epsilon^{p}$ according to

$$
\phi\left(\epsilon^{p}\right)=\max \left(\phi_{\infty}, \phi_{0}-\frac{\epsilon^{p}\left(\phi_{0}-\phi_{\infty}\right)}{\epsilon_{\infty}^{p}}\right) .
$$

Eq. (A.9) defines an empirical softening relation which reduces the friction angle linearly with accumulated plastic strain. Here $\phi_{0}$ defines the initial friction angle. $\epsilon_{\infty}^{p}$ represents the measure of plastic strain after which complete softening is achieved and internal friction angle reaches $\phi_{\infty}$. Plastic strain represents an integrated, tensorial invariant measure of the deformation which has occurred due to plastic yielding. Thus, the quantity $\epsilon^{p}$ can be regarded as a simplified measure of material damage. The evolution of plastic strain is given by;

$$
\frac{D \epsilon^{p}}{D t}= \begin{cases}\dot{\varepsilon}_{I I}, & \text { if } \eta^{\prime}>\tau_{y} / 2 \dot{\varepsilon}_{I I} \\ 0, & \text { otherwise }\end{cases}
$$

where $\dot{\varepsilon}_{I I}=\frac{1}{2} \sqrt{\dot{\varepsilon}_{i j} \dot{\varepsilon}_{i j}}$. The effective viscosity $\eta$ is computed on markers and account for both the parametrised creeping of viscous rocks and brittle behaviour following

$$
\eta=\min \left[\eta^{\prime}, \frac{\tau_{y}}{2 \dot{\varepsilon}_{I I}}\right] .
$$

\section{Appendix B. Numerical Aspects}

pTatin3D employs an inf-sup stable mixed Finite Element method with an Arbitrary Lagrangian Eulerian description to solve the discrete incompressible Stokes problem given by Eqs. (A.1) and (A.4). The velocity field is discretised via a $Q_{2}$ (tri-quadratic) basis, whilst the pressure field is discretised via a $P_{1}^{\text {disc }}$ (piece-wise linear) basis which is discontinuous across element boundaries.

The material-point-method is used to discretise different material regions. In the materialpoint-method, Lagrangian particles are introduced within each finite element. The particles are advected with the velocity computed from the solution of the discrete Stokes problem. Each particle stores an indexing used to identify to which material region it belongs to. This index is used to determine the value of the rheological constants and coefficients related to Boussinesq. The particles are also used to store the plastic strain $\epsilon^{p}$.

At each material point we evaluate the viscous flow-law and the Drucker-Prager yield stress. The effective viscosity (see Eq. (A.11)) is also evaluated at each material point. We define an 


\footnotetext{
${ }^{1}$ upon request during review process, when the paper gets accepted the code will be accessible with no restrictions
} a similar manner, but use the arithmetic average of marker densities.

We apply the Flexible-GMRES (Saad, 1993) Krylov method to solve Eq. (A.1). The system is right preconditioned using an upper block triangular preconditioner (Elman et al., 2005). The viscous block is preconditioned using a hybrid geometric multigrid implementation (May et al., 2015).

The temperature $T$ in Eq. (A.6) is discretised using $Q_{1}$ finite elements which overlap the $Q_{2}$ velocity space. The advection-diffusion equation is stabilized via SUPG (Brooks and Hughes, 1982). The Stokes problem and energy equation are solved in a de-coupled manner, thus the temperature dependence in the rheology (Eq. (A.7)) and forcing function (Eq. (A.5)) does not introduce an additional non-linearity.

Support for all parallel linear algebra, in the form of matrices, vectors, preconditioners, Krylov methods and nonlinear solvers is provided by PETSc (Balay et al., 2013b,a). Parallelism is achieved by spatially decomposing the structured finite element (FE) mesh containing $M \times N \times P$ elements, into structured sub-domains containing $m \times n \times p$ elements. The underlying mesh data structure we uses is defined by DMDA object provided by PETSc.

The simulation results were performed using 512 cores an SGI ICE 8200 with compute nodes consisting of $2 \times 6$ Intel Xeon (Series 5600) cores running at $2.8 \mathrm{GHz}$. Each model required approximately 2000 time steps summing to approximately 2 days of computation time for a mesh resolution of $256 \times 32 \times 128 Q_{2}$ elements. The multigrid preconditioner was configured with three levels, from the coarsest to the finest level: $32 \times 16 \times 16,128 \times 32 \times 64,256 \times 32 \times 128$. We used conjugate gradient and incomplete LU as the coarse grid solver. The coarse grid solver was terminated after 25 iterations, or if the initial residual was reduced by a factor of $10^{4}$. The non linear solver uses picard iterations with rtol $10^{-2}$ or atol $10^{-4}$.

pTatin3D (May et al., 2014, 2015) is an open source code copyrighted under GNU General Public License v.3 and may be accessed ${ }^{1}$ at https://bitbucket.org/jedbrown/ptatin3d. pTatin3D heavily leverages functionality from PETSc, which can be freely downloaded at http://www.mcs.anl.gov/petsc. Input files are available upon request from the corresponding author.

\section{References}

average viscosity over each $Q_{2}$ element using the harmonic average of the effective viscosity associated with all material points contained in a given element. The element density is computed in 
Allken, V., Huismans, R. S., Fossen, H., Thieulot, C., 2013. 3D numerical modelling of graben interaction and linkage: a case study of the Canyonlands grabens, Utah. Basin Research 25 (4), 436-449.

URL http://dx.doi.org/10.1111/bre.12010

Allken, V., Huismans, R. S., Thieulot, C., 2011. Three-dimensional numerical modeling of upper crustal extensional systems. Journal of Geophysical Research: Solid Earth (1978-2012) $116(\mathrm{~B} 10)$.

Allken, V., Huismans, R. S., Thieulot, C., 2012. Factors controlling the mode of rift interaction in brittle-ductile coupled systems: A 3D numerical study. Geochemistry, Geophysics, Geosystems $13(5)$, Q05010.

Balay, S., Brown, J., Buschelman, K., Eijkhout, V., Gropp, W. D., Kaushik, D., Knepley, M. G., McInnes, L. C., Smith, B. F., Zhang, H., 2013a. PETSc Users Manual. Tech. Rep. ANL-95/11 - Revision 3.4, Argonne National Laboratory.

Balay, S., Brown, J., Buschelman, K., Gropp, W. D., Kaushik, D., Knepley, M. G., McInnes, L. C., Smith, B. F., Zhang, H., 2013b. PETSc Web page.

URL http://www.mcs.anl.gov/petsc

Basile, C., Mascle, J., Popoff, M., Bouillin, J., Mascle, G., 1993. The Ivory Coast-Ghana transform margin: a marginal ridge structure deduced from seismic data. Tectonophysics 222 (1), 1-19.

Bellahsen, N., Fournier, M., d'Acremont, E., Leroy, S., Daniel, J., 2006. Fault reactivation and rift localization: Northeastern Gulf of Aden margin. Tectonics 25, TC1007.

Brooks, A. N., Hughes, T. J. R., 1982. Streamline upwind/Petrov-Galerkin formulations for convection dominated flows with particular emphasis on the incompressible Navier-Stokes equations. Comput. Methods Appl. Mech. Engrg. 32 (1), 199-259.

Brune, S., 2014. Evolution of stress and fault patterns in oblique rift systems: 3-D numerical lithospheric-scale experiments from rift to breakup. Geochemistry, Geophysics, Geosystems 15, $3392-3415$.

Brune, S., Heine, C., Pérez-Gussinyé, M., Sobolev, S. V., 2014. Rift migration explains continental margin asymmetry and crustal hyper-extension. Nature Communications 5. 
Brune, S., Williams, S. E., Butterworth, N. P., Müller, R. D., 2016. Abrupt plate accelerations shape rifted continental margins. Nature 536 (7615), 201-204.

Bullard, E., Everett, J. E., Smith, A. G., 1965. The fit of the continents around the Atlantic. Philosophical Transactions of the Royal Society of London A: Mathematical, Physical and Engineering Sciences 258 (1088), 41-51.

Choi, E., Lavier, L., Gurnis, M., 2008. Thermomechanics of mid-ocean ridge segmentation. Physics of the Earth and Planetary Interiors 171 (1), 374-386.

Elman, H., Silvester, D., Wathan, A., 2005. Finite Elements and Fast Iterative Solvers. Oxford Univ. Press, New York.

Francheteau, J., Le Pichon, X., 1972. Marginal Fracture Zones as Structural Framework of Continental Margins in South Atlantic Ocean. The American Association of Petroleum Geologist Bulletin 56, 991-1007.

Gerya, T., 2010. Dynamical instability produces transform faults at mid-ocean ridges. Science 329 (5995), 1047-1050.

Gerya, T. V., 2013. Three-dimensional thermomechanical modeling of oceanic spreading initiation and evolution. Physics of the Earth and Planetary Interiors 214, 35-52.

Heine, C., Brune, S., 2014. Oblique rifting of the Equatorial Atlantic: Why there is no Saharan Atlantic Ocean. Geology 42 (3), 211-214.

Huet, B., Le Pourhiet, L., Labrousse, L., Burov, E., Jolivet, L., 2011. Post-orogenic extension and metamorphic core complexes in a heterogeneous crust: the role of crustal layering inherited from collision. application to the cyclades (aegean domain). Geophysical Journal International $184(2), 611-625$.

Huismans, R., Beaumont, C., 2007. Roles of lithospheric strain softening and heterogeneity in determining the geometry of rifts and continental margins. Geological Society, London, Special Publications 282 (1), 111-138.

Huismans, R., Beaumont, C., 2011. Depth-dependent extension, two-stage breakup and cratonic underplating at rifted margins. Nature 473 (7345), 74-78. 
Le Calvez, J. H., Vendeville, B. C., 2002. Experimental designs to model along-strike fault interaction. Analogue modelling of large-scale tectonic processes. J Virtual Explorer 7, 7-23.

Leroy, S., Lucazeau, F., d'Acremont, E., Watremez, L., Autin, J., Rouzo, S., Bellahsen, N., Tiberi, C., Ebinger, C., Beslier, M.-O., et al., 2010. Contrasted styles of rifting in the eastern Gulf of Aden: A combined wide-angle, multichannel seismic, and heat flow survey. Geochemistry, Geophysics, Geosystems 11 (7).

Leroy, S., Razin, P., Autin, J., Bache, F., d?Acremont, E., Watremez, L., Robinet, J., Baurion, C., Denèle, Y., Bellahsen, N., et al., 2012. From rifting to oceanic spreading in the Gulf of Aden: a synthesis. Arabian Journal of Geosciences 5 (5), 859-901.

Liao, J., Gerya, T., 2015. From continental rifting to seafloor spreading: Insight from 3d thermomechanical modeling. Gondwana Research 28 (4), 1329-1343.

Manighetti, I., Tapponnier, P., Courtillot, V., Gruszow, S., Gillot, P., 1997. Propagation rifling along the Arabia-Somalia plate boundary: The Gulfs of Aden and Tadjoura. Journal of Geophysical Research 102, 2681-2710.

Mart, Y., Dauteuil, O., 1999. Analogue experiments of propagation of oblique rifts. Tectonophysics $316,121-132$.

Mascle, J., Blarez, E., 1987. Evidence for transform margin evolution from the Ivrory Coast-Ghana continental margin. Nature 326, 378-381.

Maus, S., Barckhausen, U., Berkenbosch, H., Bournas, N., Brozena, J., Childers, V., Dostaler, F., Fairhead, J., Finn, C., Von Frese, R., et al., 2009. Emag2: A 2-arc min resolution earth magnetic anomaly grid compiled from satellite, airborne, and marine magnetic measurements. Geochemistry, Geophysics, Geosystems 10 (8).

May, D., Brown, J., Le Pourhiet, L., 2015. A scalable, matrix-free multigrid preconditioner for finite element discretizations of heterogeneous Stokes flow. Comput. Methods Appl. Mech. Engrg. 290, 496-523.

May, D. A., Brown, J., Le Pourhiet, L., 2014. pTatin3D: high-performance methods for longterm lithospheric dynamics. Proceedings of the International Conference for High Performance Computing, Networking, Storage and Analysis, 274-284. 
McClay, K., 1990. Extensional fault systems in sedimentary basins: a review of analogue model studies. Marine and Petroleum Geology 7, 206-233.

Moulin, M., Aslanian, D., Unternehr, P., 2009. A new starting point for the South and Equatorial Atlantic Ocean. Earth-Science Reviews 98, 1-37.

Pérez-Gussinyé, M., Reston, T., Morgan, J. P., 2001. Serpentinization and magmatism during extension at non-volcanic margins: the effect of initial lithospheric structure. Geological Society, London, Special Publications 187 (1), 551-576.

Péron-Pinvidic, G., Manatschal, G., 2010. From microcontinents to extensional allochthons: witnesses of how continents rift and break apart? Petroleum Geoscience 16 (3), 189-197.

Rabinowitz, P. D., LaBrecque, J., 1979. The Mesozoic South Atlantic Ocean and evolution of its continental margins. Journal of Geophysical Research: Solid Earth 84 (B11), 5973-6002.

Ranero, C. R., Pérez-Gussinyé, M., 2010. Sequential faulting explains the asymmetry and extension discrepancy of conjugate margins. Nature 468 (7321), 294-299.

Rüpke, L. H., Schmid, D. W., Hartz, E. H., Martinsen, B., 2010. Basin modelling of a transform margin setting: structural, thermal and hydrocarbon evolution of the Tano Basin, Ghana. Petroleum Geoscience 16 (3), 283-298.

Saad, Y., 1993. A flexible inner-outer preconditioned GMRES algorithm. SIAM J. Sci. Comput. $14(2), 461-469$.

Torsvik, T. H., Rousse, S., Labails, C., Smethurst, M. A., 2009. A new scheme for the opening of the South Atlantic Ocean and the dissection of an Aptian salt basin. Geophysical Journal International 177 (3), 1315-1333.

Tron, V., Brun, J.-P., 1991. Experiments on oblique rifts in brittle-ductile systems. Tectonophysics $188,71-84$.

Turner, J. P., Rosendahl, B. R., Wilson, P. G., 2003. Structure and evolution of an obliquely sheared continental margin: Rio Muni, West Africa. Tectonophysics 374 (1), 41-55.

Unternehr, P., Olivet, J. L., Goslin, J., Beuzart, P., 1988. South Atlantic fits and intraplate boundaries in Africa and South America. Tectonophysics 155 (1-4), 169-179. 
Unternehr, P., Péron-Pinvidic, G., Manatschal, G., Sutra, E., 2010. Hyper-extended crust in the South Atlantic: in search of a model. Petroleum Geoscience 16 (3), 207-215.

van Wijk, J. W., 2005. Role of weak zone orientation in continental lithosphere extension. Geophysical Research Letters 32 (2), L02303.

URL http://dx.doi.org/10.1029/2004GL022192

Vendeville, B., Le Calvez, J., 1995. Physical models of normal-fault relays between variably offset grabens. AAPG Bulletin 79 (CONF-950995-).

Vink, G. E., 1982. Continental rifting and the implications for plate tectonic reconstructions. Journal of Geophysical Research: Solid Earth 87 (B13), 10677-10688.

Watremez, L., Burov, E., d’Acremont, E., Leroy, S., Huet, B., Le Pourhiet, L., Bellahsen, N., 2013. Buoyancy and localizing properties of continental mantle lithosphere: Insights from thermomechanical models of the eastern gulf of aden. Geochemistry, Geophysics, Geosystems 14 (8), $2800-2817$. 